\title{
Assessing doses to humans in the Posiva safety case
}

\author{
T. Hjerpe ${ }^{1}$, A.T.K. Ikonen ${ }^{2}$ and R. Broed ${ }^{3}$ \\ ${ }^{1}$ Saanio Riekkola Oy, Laulukuja 4, Fl-00420 Helsinki, Finland \\ ${ }^{2}$ Posiva Oy, Olkiluoto, Fl-27160 Eurajoki, Finland \\ ${ }^{3}$ Facilia AB, Gustavslundsvägen 151C, SE-16751 Bromma, Sweden
}

\begin{abstract}
In Finland, Olkiluoto Island has been selected for constructing a spent nuclear fuel disposal facility. With the approaching licensing step, submitting the application for nuclear construction licence in 2012, all components of the safety case are becoming more site-specific. In order to assess compliance with regulatory requirements, a prospective deterministic dose assessment methodology based on the ICRP concept of assessing doses to the representative person was developed and implemented in the interim safety case 2009, to be further refined for the safety case 2012. To facilitate the assessment of doses to the most exposed people and other people at the evolving site, full dose distributions are derived, comprising the dose to each potentially exposed person in each generation.
\end{abstract}

\section{INTRODUCTION}

Posiva Oy is implementing a repository programme in Finland; spent nuclear fuel is to be disposed of in a KBS-3 type of repository at a depth of about 420 metres in the bedrock of Olkiluoto Island, the selected site on the western coast. The next milestone in the licensing process is to submit the application for the nuclear construction licence by 2012. A safety case is currently being produced to support this application, preceded by an interim safety case in 2009 [1]. A key contributor to the safety case is the biosphere assessment, (e.g. [2]), with the overall aims of describing the future, present, and relevant past conditions at, and prevailing processes in, the surface environment of the Olkiluoto site experiencing the post-glacial bedrock rebound; modelling the transport and fate of postulated radionuclide releases in the surface environment; and assess the potential radiological consequences to humans and other biota. With the approaching licensing step, increased degree of site-specificity and the necessity to show compliance with all regulatory requirements are becoming more pronounced. This paper discusses the regulatory requirements to the dose assessment, and presents a methodology for dose assessment proposed to be applied in the safety case 2012 . Selected results from applying the methodology on environmental media concentrations from the interim safety case 2009 are also presented.

\section{REGULATORY REQUIREMENTS AND GUIDANCE ON THE DOSE ASSESSMENT}

In addition to the regulatory requirements on the dose assessment, refined from the legislation by the Radiation and Nuclear Safety Authority (STUK), Posiva is also striving to be in line with the recommendations provided by the International Commission on Radiological Protection in [4, 5].

Nuclear waste management is in Finland regulated by the Nuclear Energy Act (990/1987), the Nuclear Energy Decree (161/1988). An amended to the Nuclear Energy Act has also been issued including new decrees, such as the Government Decree (736/2008) on the Safety of Disposal of Nuclear Waste was issued, which sets out the basic regulatory requirements for the long-term safety. More details are set out in the STUK Guide YVL D.5 on disposal of nuclear waste, currently in a mature draft stage [3]. The criteria for the time window for dose assessment and for protection of humans are stated as: "In any assessment period, during which the radiation exposure of humans can be assessed 
with sufficient reliability, and which shall extend at a minimum over several millennia: 1) the annual (effective) dose to the most exposed people shall remain below the value of $0.1 \mathrm{mSv}$, and 2) the average annual (effective) doses to other people shall remain insignificantly low". No fixed dose constraint is given for other people; the acceptability of the estimated doses depends on the number of exposed people, but shall not exceed 1/100 to $1 / 10$ of the constraint for the most exposed people. Furthermore, implications of changes in ground level in relation to sea need to be considered, but the climate type as well as the human habits can be assumed to remain unchanged [3]. Guidance is also provided on how to quantify the exposure to the two groups mentioned above [3]: "the dose constraint for the most exposed individuals stands for an average dose e.g. in a self-sustaining family or small village community living in the environs of the disposal site, where the highest radiation exposure arises via the various pathways", and "the average annual doses to such larger groups of people shall be addressed, who live at a regional lake or a coastal site and are exposed to the radioactive substances transported into these watercourses".

The regulations are in many aspects clear. However, a certain degree of interpretation is needed, presented here according to Posiva's understanding:

Dose assessment time window. STUK states [3] that the dose criteria are applicable in a period, during which the radiation exposure of humans can be assessed with sufficient reliability, with a minimum of several millennia. Uncertainties in predicting the conditions of the surface environment, especially in the behaviour of future human generations, will significantly increase with time. Posiva believes that assessing radiation exposure to humans is no longer sufficiently reliable beyond the round number of 10,000 years from now.

Forecasting the surface environment. STUK requires [3] that environmental changes due to be changes in ground level in relation to sea need to be considered. As the site experiences the postglacial land uplift, the location of the shoreline will most likely be displaced several kilometres within few millennia. Posiva applies a dynamic dose assessment (i.e. no steady-state dose conversion factors) based on dynamic modelling of the surface environment evolution.

Annual dose to the most exposed people. Posiva understands that assessing the annual dose to the most exposed people is the same as assessing the mean annual doses received by the critical group, as recommended by the ICRP [5]. The concept presented here is inspired by the guidance in [4] on how to assess the dose to the 'representative person' (which is considered to be equivalent to an 'average member of the critical group').

Average annual doses to other people. STUK states [3] that this group lives at regional lake or a coastal site. To estimate average doses, the number of exposed persons is needed. STUK states [3] that human habits can be assumed to remain unchanged; Posiva assumes the present-day demographic throughout the whole dose assessment. The approach to assess doses to other people is cautiously based on deriving average doses to all inhabitants, excluding the most exposed group, at or near the site. Regional collective dose commitments from radionuclide releases into water bodies will also be derived based on the methodology in UNSCEAR [6]. These concepts are further elaborated below.

\section{METHODOLOGY}

The dose assessment follows the general process in Figure 1; this work focuses on how results from radionuclide transport modelling are converted to dose estimates suitable for compliance assessment. A prospective deterministic approach was developed and applied in the interim safety case 2009 [2-7] and developed further for the safety case 2012 as presented below.

\subsection{Environmental information}

The key information needed for the dose assessments is radionuclide-specific radioactivity concentrations in soils, sediments and water. In Posiva's assessment, this information is produced in 


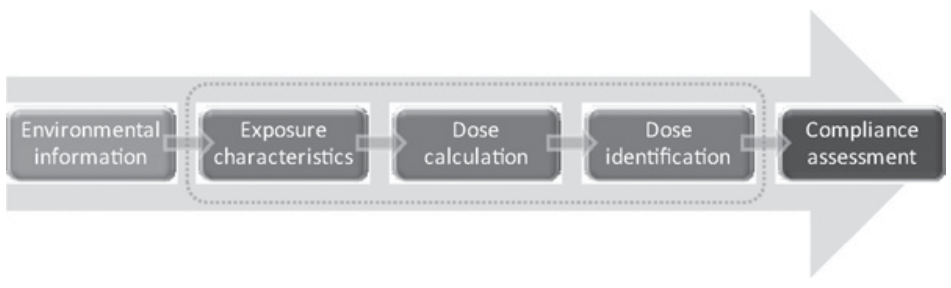

Figure 1. General process for assessing the doses to humans.

landscape modelling [2-7]. Using forecasts of the surface environment conditions, continuous and homogeneous sub-areas (biosphere objects) that could potentially receive the radionuclides releases are identified. The output is time-dependent and radionuclide-specific activity distributions in the model compartments (e.g., soil layers and plants). Additionally, production rates of individual food products and aggregated concentration ratios of radionuclides from environmental media to food products are needed.

\subsection{Exposure characteristics}

In general, diet, occupancy, and other information needed to estimate exposure may be referred to as 'habit data' [4]. The applied characteristics are based mainly on site-specific conditions, regional land use, and present-day human habits in the region. A few exceptions are food and water demands, selected to intake rates commonly used in risk and safety assessments. Key aspects in Posiva's dose assessment include:

Exposure pathways. Ingestion of food (including milk) from aquatic and terrestrial ecosystems, ingestion of drinking water from freshwater bodies and wells, inhalation of contaminated air and external exposure from ground are considered.

Use of local resources. To ensure that the doses, especially to the most exposed people, are not underestimated, the very cautious assumption is made that all consumed food and water originate from the contaminated areas, i.e. no credit for importing foodstuff. Furthermore it is assumed that all contaminated edibles are consumed, and that humans have no preferences regarding food.

Size of the exposed population. The maximum number of exposed persons is limited by the capability of the site to produce food to humans (related to food ingestion), and by the size of suitable residential areas and present demography (related to inhalation and external exposure). There is also a limitation due to ingestion of water: as even a rather small river or lake may provide drinking water to a large population (in this context), the exposed population is fixed number based on the present demography, all people assumed to draw their drinking water from the most contaminated freshwater object. In practice, the population that may be sustained by contaminated drinking water is expected to be the highest; only when no contaminated freshwater object exists, the size of the group will be limited by the other pathways.

To get also a rough estimate on the potential impact of using all contaminated water, regional collective dose commitments will also be derived as an alternative line of reasoning. This will be done by applying the generic results proposed by UNSCEAR; the methodology is presented in detail in [6] and is only briefly discussed below. The exposure pathways considered are drinking of freshwater from both surface and ground sources, and consumption of biota living in the water, typically fish.

\subsection{Dose calculation}

The approach is to calculate landscape doses $\left(E_{\mathrm{L}}\right)$, defined as the pathway-, radionuclide- and biosphere object-specific annual effective dose to an individual (described in details in $[7,8]$ ). In the calculations, 
the inhalation and external exposure pathways are combined into one dose quantity $\left(E_{\mathrm{L}, \mathrm{IE}}\right)$ as the external exposure from ground and inhalation of air occur simultaneously, at the same location. The doses arising from ingestion of food $\left(E_{\mathrm{L}, \mathrm{F}}\right)$ and water consumption $\left(E_{\mathrm{L}, \mathrm{W}}\right)$ are kept separate. The landscape dose from food ingestion $\left(E_{\mathrm{L}, \mathrm{F}}\right)$ is the product of the annual intake of a radionuclide from ingestion of food and the corresponding dose coefficient for ingestion, the landscape dose from water consumption $\left(E_{\mathrm{L}, \mathrm{W}}\right)$ is the product of the annual intake of a radionuclide from water consumption and the corresponding dose coefficient for ingestion, and the landscape dose from inhalation and external exposure $\left(E_{\mathrm{L}, \mathrm{IE}}\right)$ is the product of the annual intake of a radionuclide via inhalation and the corresponding dose coefficient for inhalation summed with the activity concentration in the ground and the corresponding dose coefficient for external exposure. $E_{\mathrm{L}, \mathrm{W}}$ is calculated for lakes, rivers and water wells, and $E_{\mathrm{L}, \mathrm{IE}}$ is calculated for terrestrial objects, i.e., forests, wetlands and croplands.

A key parameter needed in the dose identification below is the highest numbers of people (maximum sustainable populations) that can satisfy their annual demands of food, drinking water, and residential areas by utilising the respective contaminated resources. These are derived for each exposure pathway discusses above as follows: The maximum sustainable population limited by food ingestion $\left(N_{\mathrm{F}}\right)$ is the amount of all contaminated edibles produced annually divided by the average annual food demand by an individual. The maximum sustainable population limited by inhalation and external exposure $\left(N_{\mathrm{IE}}\right)$ is derived by dividing the total suitable residential area by a postulated population density. The maximum sustainable population limited by water intake $\left(N_{\mathrm{W}}\right)$ is selected to 6000 persons, which is approximately the present regional population.

Regional collective dose commitments for radionuclide releases to the aquatic environment are calculated by applying the UNSCEAR methodology [6]. UNSCEAR have, based on assumptions on generally applicable values and crude approximations, derived estimates of radionuclide-specific collective dose commitments per unit activity release of a radionuclide to the aquatic environment, both to freshwater and salt water for many radionuclides of which only I-129 and C-14 are of importance in Posiva's case. However, I-129 and C-14 are expected to dominate the annual doses, in most scenarios, within the first 10,000 years [2]. Hence, deriving regional collective dose commitments from these two radionuclides is considered to represent fairly well the order of magnitude of the total regional collective dose commitment.

\subsection{Dose identification and compliance assessment}

The pathway-specific landscape doses are combined to obtain the annual landscape dose $E_{\mathrm{ALD}} . E_{\mathrm{ALD}}$ is the sum of the dose maxima from each pathway. As long as possible, the food and water originates from the contaminated biosphere objects; thus, $E_{\mathrm{ALD}}$ may contain contributions from several objects. $E_{\mathrm{ALD}}$ is calculated for each exposed individual, forming the dose distribution of life time doses to each potentially exposed person in each generation. The most exposed group is identified as the subgroup of the exposed population that receives highest doses. The ICRP recommends, for probabilistic assessments, using the $95^{\text {th }}$ dose percentile as the basis for selection of the most exposed group and that the characteristics of these people need to be explored in the case when relevant dose constraints might be exceeded by a few tens of people or more [4]. Even though the present Posiva dose assessment is deterministic, a size of the most exposed group not larger than a few tens of people is considered appropriate; the 20 most exposed persons is selected as the most exposed group.

The group of other people is here selected in two ways, considered to represent an exposed local and a regional group. The size of the local group is selected to the highest of $N_{\mathrm{F}}$ and $N_{\mathrm{IE}}$, excluding the most exposed group. The size of the regional group is selected as the whole exposed population, excluding the most exposed group. Thus the size of the regional exposed group will be constant and the size of the local group will be dependent on the landscape model evolution (its capability to produce food and supply humans with suitable residential areas). As the final step, the annual doses to three representative persons are identified as follows: the annual landscape dose to a representative person 


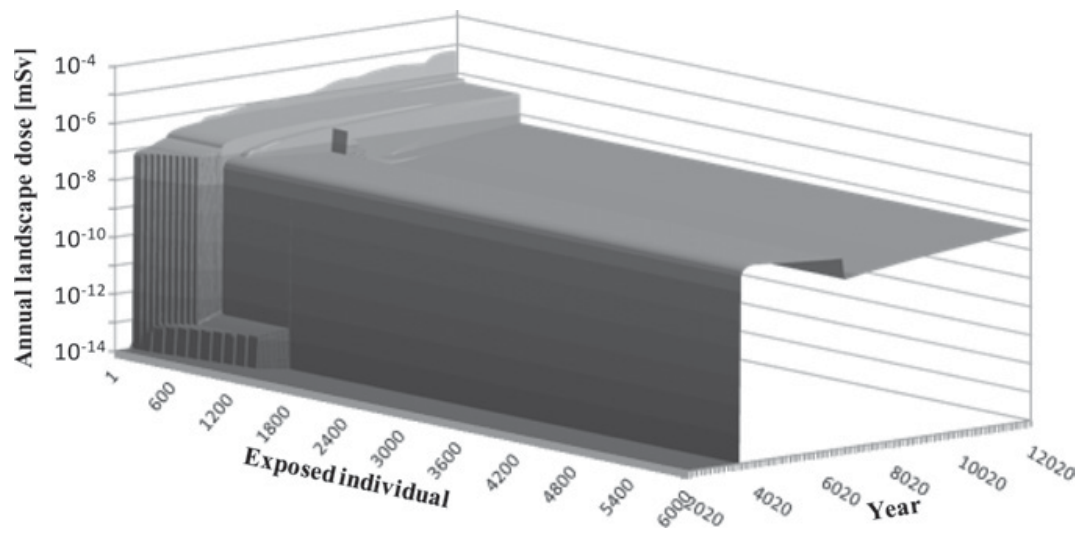

Figure 2. The resulting dose distribution when applying the dose assessment methodology on calculation case Sh1A from the interim safety case 2009 [2].

within the most exposed group ( $\left.E_{\mathrm{most} . \mathrm{exp}}\right)$ is the average $E_{\mathrm{ALD}}$ for all individuals in the most exposed group; the annual landscape dose to a representative person among other local people $\left(E_{\text {local }}\right)$ is the average $E_{\mathrm{ALD}}$ in the exposed local group; and the annual landscape dose to a representative person among other regional people $\left(E_{\text {regional }}\right)$ is the average $E_{\mathrm{ALD}}$ in the exposed regional group. The highest doses, over all generations, are then used to evaluate compliance with the regulatory dose constraints to most exposed persons and to other people.

Collective doses, for other local and regional people, are derived from the dose distribution. Also regional collective dose commitments are derived, to get a rough estimate on the potential impact of humans utilising all contaminated water bodies. Hence, three collective doses are identified: $S_{\text {local }}$ as the sum of all $E_{\mathrm{ALD}}$ in the exposed local group, $S_{\text {regional1 }}$ as the sum of all $E_{\mathrm{ALD}}$ in the exposed regional group, and $S_{\text {regional } 2}$ by multiplying the collective dose commitments per unit activity release to aquatic environment [6] with the estimated radionuclide releases (of C-14 and I-129) into water bodies. In order to assess compliance with the regulatory constraints, the whole assessment time window shall be considered. This is done by deriving the dose distribution for each generation and identifying the doses to representative persons as described above. The derived collective doses are used as supporting arguments in the compliance assessment.

\section{RESULTS AND DISCUSSION}

The methodology presented above is demonstrated on one of the reference assessment calculation cases in the interim safety case 2009 [1]. The selected calculation case, Sh1A, assumes a single canister with an initial small hole with $1 \mathrm{~mm}$ diameter in the copper overpack, at the time of emplacement [2-9]. The calculated geosphere release rates [9] were then analysed with the landscape model to derive timedependent and radionuclide-specific activity concentrations in all biosphere objects in the landscape model [2]. The resulting dose distribution from the analysis of the calculation case Sh1A is presented in Figure 2. The annual landscape doses to representative persons within the most exposed group, local other people and regional other people derived from Figure 2 are shown in Figure 3, together with the number of persons within each group. The resulting collective doses as defined in section 3.4 are presented in Figure 4.

Based on the Figures 2-4 it can be observed that (1) the number of exposed persons in the region is less than 6000 up to year 3570 , resulting from no contaminated freshwater bodies existing yet; $N_{\mathrm{F}}$ is then the limiting parameter; (2) beyond year 3570, the whole exposed population, 6000 persons, draw their drinking water from the same freshwater source, i.e. when $N_{\mathrm{F}}$ and $N_{\mathrm{IE}}$ have been exceeded, the 


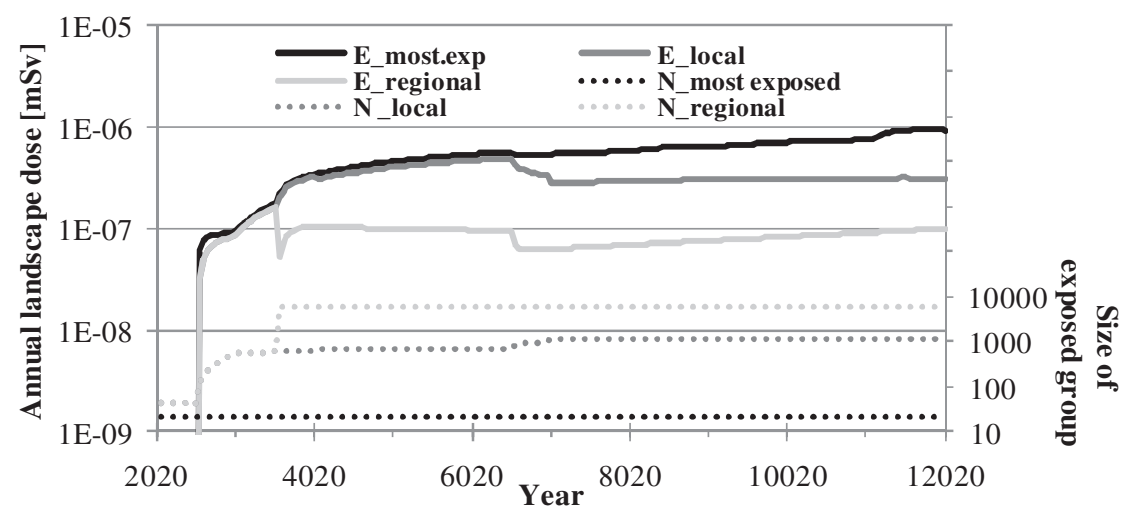

Figure 3. Annual landscape doses to representative persons within the most e0xposed group (E_most.exp), other local people (E_local), and other regional people (E_regional), and the sizes of the groups (dotted lines).

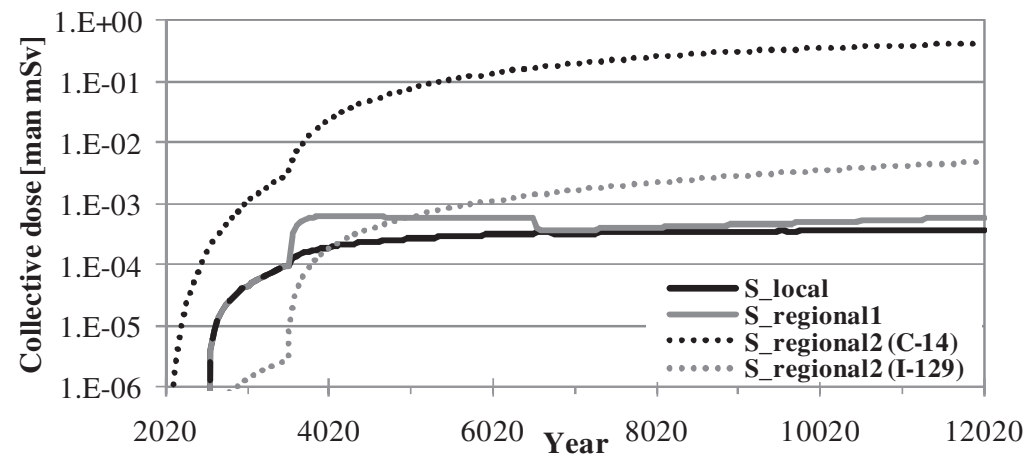

Figure 4. Collective annual landscape doses to the exposed local group (S_local) and regional group (S_regional1), and the collective dose commitment (S_regional2) for the two key radionuclides C-14 and I-129.

dose to all remaining exposed persons becomes the same; (3) the dose maximum to a representative person of the most exposed group ( $E_{\text {most.exp }}$ ) is about $10^{-6} \mathrm{mSv}$, which is several orders of magnitude below the regulatory constraint of $0.1 \mathrm{mSv}$; (4) the annual landscape dose maxima to representative persons among other exposed people ( $E_{\text {local }}$ and $\left.E_{\text {regional }}\right)$ are both below $10^{-6} \mathrm{mSv}$, which also is several orders of magnitude below the boundary of the regulatory constraint band $\left(10^{-3}-10^{-2} \mathrm{mSv}\right)$; and (5) the collective doses are all below 1 man $\mathrm{mSv}$.

\section{References}

[1] Posiva. Interim Summary Report of the Safety Case 2009. Posiva Oy, Report 201002 (2010).

[2] T. Hjerpe, A.T.K. Ikonen, R. Broed. Biosphere Assessment Report 2009. Posiva Oy, Report 201003 (2010).

[3] Radiation and Nuclear Safety Authority (STUK). Disposal of nuclear waste. Guide YVL D.5. Draft 3, 10.5.2010, in English. (2010).

[4] International Commission on Radiological Protection (ICRP). Assessing Dose of the Representative Person for the Purpose of Radiation Protection of the Public and the Optimisation of Radiological Protection: Broadening the Process. ICRP Publication 101. Annals of the ICRP $36: 3$ (2007). 
[5] International Commission on Radiological Protection (ICRP). Radiation protection recommendations as applied to the disposal of long-lived solid radioactive waste. ICRP Publication 81. Annals of the ICRP 28:4 (2000).

[6] United Nations Scientific Committee on the Effects of Atomic Radiation UNSCEAR 2000 Report to the General Assembly, with scientific annexes. UNSCEAR 2000 REPORT Vol. I: Annex A: Dose assessment methodologies (2000).

[7] T. Hjerpe, R. Broed. Radionuclide Transport and Dose Assessment Modelling in Biosphere Assessment 2009. Posiva Oy, Working Report 2010-79 (2010).

[8] R. Avila, U. Bergström. Methodology for calculation of doses to man and implementation in PANDORA. Posiva Oy, Working Report 2006-56 (2006).

[9] M. Nykyri, H. Nordman, N. Marcos, J. Löfman, A. Poteri, A. Hautojärvi. Radionuclide Release and Transport - RNT-2008. Posiva Oy, Report 2008-06 (2008). 